ally significant) in the surgical group died or became persistently vegetative in the postoperative period; more $(p<0.05)$ also made a good recovery.

If we assume their groups were similar the only conclusion that can be drawn is that burr hole biopsy -a diagnostic procedure-may place the patient at risk of neurological worsening. Biopsy of a large tumour may be more dangerous than resection because postoperative swelling may cause neurological deterioration. The authors' "conservative approach" (fig 1) yields a median survival of about five months considerably less than the median survival of 12 months found in most large series of malignant gliomas treated with surgery, radiation, and chemotherapy. Their data are even worse when one considers that a significant number of low grade gliomas are included.

We examined, the day before surgery and at discharge, 66 patients who underwent craniotomy for excision of malignant gliomas. We assessed the extent of resection by postoperative computed tomography Twenty five (38\%) of our patients were undergoing second operations after relapse and were thus poor risk patients. Ail were on maximal doses of steroids before operation. Thus our patients differed from those of $\mathrm{Dr}$ Wroe and colleagues in that their baseline performance included the improvement caused by steroids. Most patients had a complete or subtotal resection. The operative mortality was $5 \%$ and neurological worsening was $7 \%$. The outcome of surgery was as good in those patients undergoing complete resection as in those undergoing biopsy. No patients became vegetative. The mortality of these high risk patients was lower than that of either of the author's neurological or neurosurgical patients and the rate of good recovery was higher. Furthermore, a review of 300 malignant gliomas showed that over twice as many patients with extensive tumour resection $\left(\leqslant 100 \mathrm{~mm}^{2}\right.$ on postoperative computed tomography) lived over two years as those with less extensive resections.

We agree with them that craniotomy and bur hole biopsy are usually not indicated as the sole approach to managing patients with brain tumours and may be harmful. We strongly disagree that a "conservative approach" with steroids alone is indicated and that "medical neurologists differ from their neurosurgical colleagues in their approach to the management of patients with malignant primary brain tumours." The undersigned medical neurologists do not so differ.

CAMIlo E FAdUL

WILLIAM R SHAPIRO JEROME B POSNER

Department of Neurology, Memorial Sloan-Kettering Cancer Center, New York, NY 10021, USA

1 Shapiro WR. Therapy of adult malignant brain tumours; what have the clinical trials taught us? Semin Oncol 1986;13:38-45. 2 Green SB, Byar DP, Walker MD, et al. Comparisons of carmustine, procarbazine, and high-dose methylprednisolon as additions to surgery and radiotherapy for the treatment of malignant glioma. Cancer Treat Rep 1983;67:121-5.

\section{Doctors and the drug industry}

SIR,-Caroline Richmond's naive contribution (6 December, $p$ 1507) would be best ignored if it were not for her closing allegations. The brand new medical adviser may be impressed by computer assisted data searches, but these services are widely available to all professional investigators-for example, via the libraries of the British Medica Association and the Royal Society of Medicine.

Those of us who have some experience within the pharmaceutical industry do not recognise the passive investigator she presents. The investigators who work with us are scientists with opinions of their own and total freedom of access to data. They are not work shy or spineless for they have to maintain their credibility in a highly competitive world. The word processor, now generally available, can produce an immaculate text but this serves only as the beginning for fruitful discussions and endless changes before a paper is finalised in which all concerned strive to present the scientific facts. Beyond this, the processes of peer review will begin, and Ms Richmond in her desire to make allegations of sinister implications perhaps forgot about this. Ms Richmond, you have been misled and should check your facts more carefully before rushing into print.

\section{Ciba-Geigy Pharmaceuticals,}

Horsham,

West Sussex RH12 4AB

\section{Pelvic pain in women}

SIR,-In response to our algorithm on the management of pelvic pain (1 November, $p$ 1161) Dr KW Heaton (6 December, $p$ 1504) suggests that we have overlooked the importance of the irritable bowel syndrome. However, women with the pelvic pain syndrome with dilated pelvic veins, vascular stasis, and frequently polycystic ovaries presen somewhat differently from those with the irritable bowel syndrome. They have a tendency to anxiety and depression in common ${ }^{1}$ but specifically do not have bowel symptoms.

In our algorithm we proposed that women with non-gynaecological conditions should be referred for "appropriate treatment." The fact that gynaecologists do not often see women with irritable bowel syndrome suggests that genera practitioners are already providing appropriate treatment, which may include referring them to gastroenterologists.

We would agree with Dr Heaton that gynaecologists and gastroenterologists (and, we would add, those who treat breast and facial pain, chronic backache, and chronic perineal pain, to name but a few) should get together to discuss conditions which have emotional disturbance as a major component of their symptom complex. There is a real need to sort out "cause and effect" in the aetiology of these conditions and to devise appropriate psychotherapy as a part of the therapeutic armamentarium which is available for the management of the many women and men suffering from these conditions.

R W BEARD

Philip Reginal

Department of Obstetrics and Gynaecology, Shirley Pearce

St Mary's Hospital Medical School,

London W2 1 PG

1 Beard RW, Belsey EN, Lieberman BA, Wilkinson JCM. Pelvic pain in women. Am J Obstet Gynecol 1977; 128:566-70.

\section{Cost of anaesthetic drugs and} clinical budgeting

SIR,-Drs J R Lethbridge and J Secker Walker (13 December, $p$ 1587) highlight the problems of clinical budgeting in anaesthesia, a specialty in which modern drugs inevitably cost more in real terms than older agents. They contend that the study illustrates serious problems for the holder of the budget for anaesthetic drugs.

There is no doubt that general managers would question the sharp increase in cost of anaesthetic drugs between 1980 and 1985 , particularly when "the caseload remained roughly equal for each of the two years under study." Indeed, the almost identical quantities of nitrous oxide purchased (675 G size, each costing $£ 12.20$ in $1980 ; 669 \mathrm{G}$ size, each costing $£ 10.93$ in 1985) would appear to support that statement.

However, a breakdown of the figures in table I shows the following results. Firstly, the amount of suxamethonium purchased in 1985 (11088 ampoules) was $34 \%$ higher than that purchased in

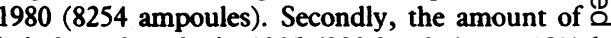
halothane bought in 1985 (920 bottles) was 19\% c higher than that bought in 1980 ( 770 bottles). This $\widehat{O}$ rise occurred despite the authors' assertion that $\overline{\bar{J}}$ "there has been a corresponding decrease in the 7 use of halothane," and despite the sixfold increase $\mathbb{D}$ in the purchase of enflurane.

If the caseload was roughly the same for each of 0 the two years the above quoted increases suggest not only a change in anaesthetic practice (as with $\stackrel{5}{\rightarrow}$ enflurane) but also that purchasing arrangements 7 did not necessarily equate with anaesthetic drug 등 use. Thus part of the explanation for the real rise in $\overline{\bar{c}}$ cost between 1980 and 1985 might have been $\widehat{\Phi}$ related to a variable pattern in purchasing arrange- $\varrho$ ments with, for example, a run down in reserve $\approx$ stocks during 1980 and then a build up in reserves $\vec{\circ}$ in 1985 (when inflation was low and reserves were diminished).

There is one other, more important, point. The $\stackrel{\omega}{\sigma}$ article also highlights the problems of clinical $\frac{5}{5}$ budgeting when taken in isolation. Most modern drugs and techniques gain acceptance when they produce demonstrable benefits to the patient. $A$ While management may consider the immediate of costs of the drugs, do they make allowance for $O$ greater patient safety, improved patient acceptance, decreased deleterious side effects, shorter recovery times, lessened use of expensive recovery facilities, and earlier postoperative discharges? These potential benefits from modern techniques and drugs may reduce dramatically patient costs 0 overall, but at the same time they may result in $C$ increased costs to the anaesthetic budget.

Perhaps our beleaguered budget holders may शे bring these factors into their discussions with management.

JW O'Higgins $\stackrel{\infty}{Ð}$

Sir Humphrey Davy Department of

Anaesthesia,

Bristol Royal Infirmary,

Bristol BS2 8HW

\section{BMA council elections}

SIR,-I have just spent some time puzzling over the ballot paper for the 1987-8 council.

Like most of your GP members I am keen to vote, but most of the candidates are just names to me and frankly the "brief particulars" did not help very much. I can glean that a candidate is young or female or experienced in committee work ior against nuclear weapons but little about medical 3 policies. Phrases such as "safeguard the profession's interests," "the BMA needs even more new ideas," and "united BMA council" mean very little. Do I vote for someone with experience or $\frac{\text { S }}{2}$ someone who sounds a bit like myself? Or is this $N$ "democracy" so much of a lottery to the outsider that it is not worth my while voting?

Please could we have more information in future? I would be prepared to take the time to read it and $N$ use my vote responsibly. And I am sure I am not $\mathbb{\omega}^{-}$ the only one.

Bradford BD4 9 QU

Siân Cheverton

** The Secretary writes: "Careful consideration has been given to the question of finding a balance between providing enough information with voting papers to guide voters, while at the $\mathbb{D}$ same time not providing so much material that it $\sigma$ would not be read. The council decided that 50 words for each candidate would be about right, $\delta$ with committee titles counting as only one word irrespective of their length, and dates not counting at all."-ED, $B M \mathcal{F}$. 